\title{
Study of Mechanical Properties and Durability of Magnesium Phosphate Cement Matrix Containing Grinding Dust
}

\author{
D. V. Ribeiro ${ }^{\mathrm{a} *}$, J. A. M. Agnelli, M. R. Morelli \\ ${ }^{a}$ Department of Materials Science and Technology, Federal University of Bahia - UFBA, \\ Rua Aristides Novis, 02, Federação, CEP 40210-630, Salvador, BA, Brazil \\ ${ }^{\mathrm{b}}$ Department of Materials Engineering, Federal University of São Carlos - UFSCar, \\ Rod. Washington Luis, Km 235, CEP 13565-905, São Carlos, SP, Brazil
}

Received: August 31, 2012; Revised: April 7, 2013

\begin{abstract}
The acid-base cements are materials developed by means of reactions between an acid component and another basic one. This type cement belongs to the family of the so called "chemically bonded phosphate ceramics" (CBPCs), new types of inorganic materials that have special physico-chemical properties and that, in contrast to most advanced ceramics, are made by processing the material at ambient temperature. In the present work, cylindrical specimens were molded $(30 \mathrm{~mm} \times 50 \mathrm{~mm})$ with magnesium phosphate cement and grinding dust (waste from an automobile industry) which was added to ceramic matrices in varied contents ( $0 \%$ to $40 \%$ in mass). The influence of this addition with regard to phase formation and to mechanic resistance (axial compression and traction by diametrical compression) of the compositions (3, 7 and 28 days after the molding) was evaluated using a universal test machine. The samples of magnesium phosphate cement mortars containing grinding dust were then analyzed after being subjected to an accelerated aging test for a period of 1200 hours (50 days), equivalent to one year of natural aging. The results obtained showed a decrease in the compressive strength of the mortar between 28 days and 1 year of age but this loss in performance is not associated with the presence of grinding dust and the CBPCs proved highly satisfactory for the encapsulation of hazardous wastes.
\end{abstract}

Keywords: cement, $\mathrm{MgO}$, accelerated aging, durability, waste

\section{Introduction}

By definition, cement is a binder material developed from a liquid or plastic state by chemical reactions that may cause resistance and elasticity to a hardened body containing large quantities of fillers. According to this definition, three types of cements can be identified: i) hydraulic cements such as Portland cement and alumina cement, which harden by hydration when they react with water and ii) cement by precipitation, which has initial reaction (setting time) due to ion exchange reactions. The third type of cement is a material developed by the reaction between an acid component and a basic component and is therefore referred to as acid-base cement. The reaction products, usually a salt or gel, form a cement matrix in which the fillers are dispersed ${ }^{1,2}$.

This third cement group belongs to the family of Chemically Bonded Phosphate Ceramics (CBPCs), a new class of inorganic materials which possess special physicochemical properties that, unlike most advanced ceramics, are obtained by processing the material at room temperature ${ }^{3}$, and may be combined with various other materials to form composite materials that satisfy the needs of high performance materials ${ }^{1}$.

Phosphate cements possess mechanical and chemical properties that are superior to those of normal hydraulic

*e-mail: verasribeiro@hotmail.com (or Portland) cements in general, thanks to innovations in their processing and microstructural handling and to compositional modifications. The bonds in such CBPCs are a mixture of ionic, covalent and Van der Waals bonds, with a predominance of ionic and covalent bonds, whereas in traditional cement hydration products, Van der Waals and hydrogen bonds predominate.

The reaction between magnesia and acid ammonium phosphate is very rapid and exothermic, and the materials cannot be practically used as such. Thus, the use of calcined or dead-burned magnesia is suggested in the present work. Today's commercial materials are formulated with many inexpensive inert materials such as sand, fly ash, etc. to control the rate of reaction or setting time while simultaneously providing high early compressive strength. Phosphate cements for commercial applications are generally based on reactions between a metallic oxide and an acid salt or derivative of phosphoric acid ${ }^{1}$.

Immediately upon mixing the raw materials at ambient temperature, exothermic reactions occur and ammonium and magnesium phosphate phases are formed. These phases are hydrated and insoluble in water.

The main product of these reactions is a crystalline phase called struvite $\left(\mathrm{NH}_{4} \mathrm{MgPO}_{4} \cdot 6 \mathrm{H}_{2} \mathrm{O}\right)$, which results from the following reaction: 
$\mathrm{MgO}+\mathrm{NH}_{4} \mathrm{H}_{2} \mathrm{PO}_{4}+5 \mathrm{H}_{2} \mathrm{O} \rightarrow \mathrm{MgNH}_{4} \mathrm{PO}_{4} \cdot 6 \mathrm{H}_{2} \mathrm{O}$

Other phases, such the dittmarite $\left(\mathrm{NH}_{4} \mathrm{MgPO}_{4} \cdot \mathrm{H}_{2} \mathrm{O}\right)$, schertelite $\left[\left(\mathrm{NH}_{4}\right)_{2} \mathrm{MgH}_{2}\left(\mathrm{PO}_{4}\right)_{2} 4 \mathrm{H}_{2} \mathrm{O}\right]$, and stercorite $\left[\mathrm{Na}\left(\mathrm{NH}_{4}\right) \mathrm{HPO}_{4} \cdot 4 \mathrm{H}_{2} \mathrm{O}\right]$ are usually observed during hydration, while hanaite $\left[\left(\mathrm{NH}_{4}\right)_{2} \mathrm{Mg}_{3}\left(\mathrm{HPO}_{4}\right)_{4} 8 \mathrm{H}_{2} \mathrm{O}\right]$, newberyite $\left[\mathrm{MgHPO}_{4} \cdot 3 \mathrm{H}_{2} \mathrm{O}\right]$ and other phosphate hydrates are found less frequently ${ }^{4}$.

Struvite is a thermally stable phase in air up to a temperature of $55^{\circ} \mathrm{C}$, at which point it decomposes through the loss of $\mathrm{H}_{2} \mathrm{O}$ and $\mathrm{NH}_{3}$ molecules from its structure, forming an amorphous composition that corresponds chemically to $\mathrm{MgHPO}_{4}$. In the presence of water at ambient temperature, this composition can be rehydrated, forming the original phase (struvite) and other amorphous and/or crystalline phases ${ }^{2}$.

Struvite and dittmarite are chemically and structurally similar and the transformation of one into the other does not cause any microstructural damage to molded specimens ${ }^{5}$. Dittmarite is the predominant phase when the reaction is fast, and the struvite predominates when the reaction rate is slow ${ }^{5}$.

$\left(\mathrm{NH}_{4}\right)_{2} \mathrm{Mg}\left(\mathrm{HPO}_{4}\right)_{2} \cdot 4 \mathrm{H}_{2} \mathrm{O}+\mathrm{MgO}$

$+7 \mathrm{H}_{2} \mathrm{O} \rightarrow 2\left(\mathrm{NH}_{4}\right) \mathrm{MgPO}_{4} \cdot 6 \mathrm{H}_{2} \mathrm{O}$

Soudée and Péra ${ }^{4}$ suggest a mechanism of formation of these materials, whereby immediately following the addition of water to the mixture, the ammonium dihydrogen phosphate (ADP) goes into solution up to saturation while magnesia starts to be wetted. The drop in $\mathrm{pH}$ that occurs during this period leads to the dissociation of magnesia through an acid-base reaction. Crystallization of the hydrate phases begins when $\mathrm{Mg}^{+2}$ ions react with six molecules of water to form $\mathrm{Mg}\left(\mathrm{H}_{2} \mathrm{O}\right)_{6}{ }^{+2}$ compounds. These compounds replace water molecules in the wetting process of magnesia. Their size prevents new water molecules from being adsorbed onto the $\mathrm{MgO}$ surface. $\mathrm{The} \mathrm{Mg}\left(\mathrm{H}_{2} \mathrm{O}\right)_{6}{ }^{+2}$ complexes remain attached to the surface, covering it progressively. $\mathrm{PO}_{4}{ }^{3-}$ and $\mathrm{NH}_{4}{ }^{+}$ions and $\mathrm{Mg}\left(\mathrm{H}_{2} \mathrm{O}\right)_{6}{ }^{+2}$ complexes can therefore develop a struvite network. Wagh et al. ${ }^{6}$ considered that the kinetics of these transformations are very similar to those of the conventional sol-gel process of ceramics fabrication. Figure 1 gives a step-by-step illustration of the kinetics of CBPC formation.

The stabilization/solidification (S/S) allows the treatment of waste materials such as fly ash, sewage sludge, low level nuclear wastes or wastewater with a high heavy metal content. The main leaching mechanism of an element will depend on the immobilizing reagents, on the physical properties of the resulting monolith, on the leaching agent and on the environment of the system, among others ${ }^{7}$.

Magnesium phosphate cements are often used for the Stabilization/Solidification $(\mathrm{S} / \mathrm{S})$ of mixed wastes and low level nuclear wastes ${ }^{8-10}$, nickel containing wastes ${ }^{7}$, for immobilization of simulated liquid alkaline high-level waste (HLW) containing actinides, fission and corrosion products $^{11}$.

According to Vinokurov et al. ${ }^{11}$, crystalline magnesium phosphates which are analogs to natural phosphate minerals (having great physico-chemical stability in a geological medium) could be used as host matrices for

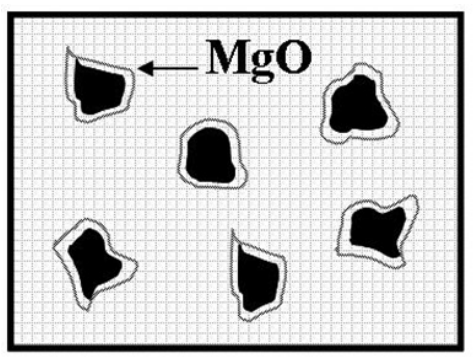

(a)

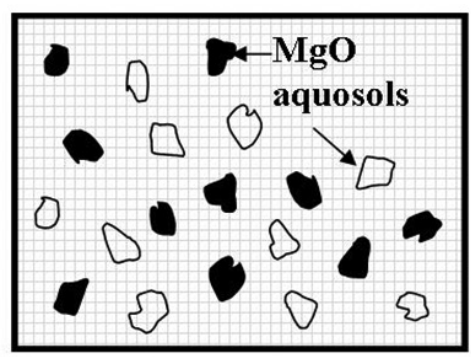

(b)

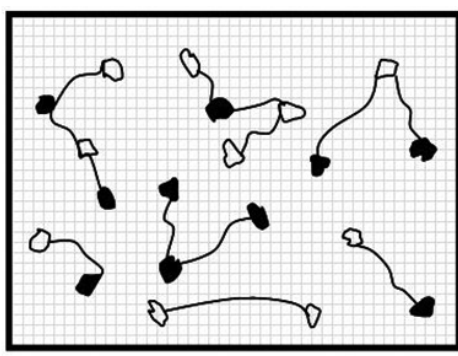

(c)

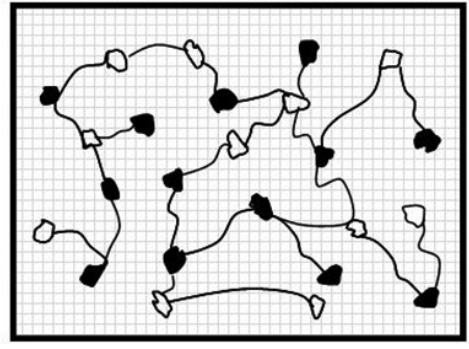

(d)

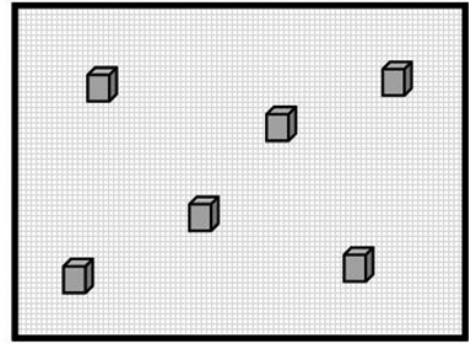

(e)

Figure 1. Pictorial representation of the formation of CBPCs: (a) Dissolution of oxides (b) formation of aquosols (c) acid-base reaction and condensation (d) percolation and formation of gel (e) crystallization and saturation of gel into a ceramic ${ }^{2}$. 
the immobilization of hazardous waste. Phosphates are extremely insoluble in groundwater and this would ensure their good isolating properties. Despite this, the matrix properties can change. Buj et al. ${ }^{9}$ observed that the presence of high concentrations of heavy metals noticeably influences the strength of the matrix regardless of the volume of permeable voids, for example.

The evaluation of cementitious materials with ages over conventionally used ones $(3,7,28$ and 90 days) is very important. The mortar specimens, with their various contents of wastes and sand were subjected to accelerated aging by ultraviolet (UV) radiation, simulating aging for 1 year.

The objective of this paper is to study the effectiveness of a magnesium phosphate cement matrix in encapsulating hazardous wastes without losing its characteristics of high performance after aging and thus to offer an alternative for the treatment of wastes that cannot be encapsulated in other cementicious matrices such as Portland cement matrix.

\section{Material and Methods}

\subsection{Materials}

In the present study a commercial dead-burned magnesium oxide calcined at $1600{ }^{\circ} \mathrm{C}$, with a $\mathrm{MgO}$ content of $88 \%$ to $93 \%$ was used. Dead-burned calcined magnesia is produced at temperatures above $1400^{\circ} \mathrm{C}$ and is characterized by its low chemical reactivity and high resistance to basic slags. The magnesium oxide presented a specific surface area of $0.81 \mathrm{~m}^{2} / \mathrm{g}$, a unitary mass of $1.34 \mathrm{~kg} / \mathrm{dm}^{3}$ and specific gravity of $3.61 \mathrm{~kg} / \mathrm{dm}^{3}$.

Ammonium dihydrogen phosphate $\left(\mathrm{NH}_{4} \mathrm{H}_{2} \mathrm{PO}_{4}\right)$, or $\mathrm{ADP}$, reacts with magnesium oxide in the presence of water in an acid-base reaction and is the source of phosphate anions for the reaction that occurs when it releases a small amount of ammonia to the atmosphere.

Recent literature reports that the amount of hydrates decreases with the amount of $\mathrm{NH}_{4} \mathrm{H}_{2} \mathrm{PO}_{4}$ and, therefore, the strength of magnesium phosphate cement (MPC) theoretically decreases ${ }^{7}$. From the proportions of MPC it can be calculated that MPC paste consists mainly of dehydrated grains of $\mathrm{MgO}$ and phosphate hydrates, and the strength of $\mathrm{MgO}$ grains is much higher than that of phosphate hydrates. Therefore, the lower the amount of ADP, the higher the strength of the MPC paste, provided that the amount of phosphate hydrates is sufficient to surround the $\mathrm{MgO}$ grains thoroughly ${ }^{12}$. The ADP presented a surface area of 0.68 $\mathrm{m}^{2} / \mathrm{g}$, unitary mass of $0.79 \mathrm{~kg} / \mathrm{dm}^{3}$ and specific gravity of $1.87 \mathrm{~kg} / \mathrm{dm}^{3}$.

The incorporation of sodium tripolyphosphate $\left(\mathrm{Na}_{5} \mathrm{P}_{3} \mathrm{O}_{10}\right)$, or simply STPP, into the magnesium phosphate mixture has a beneficial effect. The STTP acts as a retarder, increasing the reaction time, reducing the consumption rate of ADP, increasing the workability of mortar and contributing to the formation of a schertelita $\left[\left(\mathrm{NH}_{4}\right)_{2} \mathrm{Mg}\left(\mathrm{HPO}_{4}\right)_{2} \cdot 4 \mathrm{H}_{2} \mathrm{O}\right]$ phase. The deflocculating characteristics of tripolyphosphate ions suggest that they may play a significant role in enabling improved compaction of the wet mix, reducing the porosity of the hardened material ${ }^{13}$. Abdelrazig et al. ${ }^{14}$ reported that the incorporation of STPP in mortars brought about an increase in compressive strength and a decrease in total and coarse pore volumes.

The chemical compositions of $\mathrm{MgO}$, STPP, ADP and sand are shown in Table 1.

Retardants have been found to increase the setting time and reduce the intensity of exothermic reactions during the initial setting and hardening stages ${ }^{2}$. Therefore, chemical retardants are used in large-scale mixing operations. Boric acid containing about $99.5 \%$ of $\mathrm{H}_{3} \mathrm{BO}_{3}$ was used in this study.

When boric acid containing $\mathrm{MgO}$ is mixed into a phosphate solution, lunebergite $\left[\mathrm{Mg}_{3} \mathrm{~B}_{2}\left(\mathrm{PO}_{4}\right)_{2}(\mathrm{OH})_{6} \cdot 6 \mathrm{H}_{2} \mathrm{O}\right]$ is formed around the $\mathrm{MgO}$ grains, preventing them from dissolving in the acid solution ${ }^{6}$. Subsequently, as the oxide powder is mixed into the acid solution, however, the coating itself dissolves and exposes the oxide particle surface to the acid solution, and magnesium oxide then starts dissolving into the solution ${ }^{15}$.

The fine aggregate was natural siliceous sand commercially available in São Carlos, SP, Brazil. The sand presented a specific surface area of $0.68 \mathrm{~m}^{2} / \mathrm{g}$, unitary mass of $1.58 \mathrm{~kg} / \mathrm{dm}^{3}$ and specific gravity of $2.70 \mathrm{~kg} / \mathrm{dm}^{3}$.

The chemical composition of the sand to produce mortars of magnesium phosphate cement is very important because a sand-containing minerals with a high content of $\mathrm{CaO}$ (lime), such as $\mathrm{CaCO}_{3}$, is not very suitable for use. The main reason may be the fact that a key-component of CBPCs, the ammonium dihydrogen monophosphate (ADP), can easily react with $\mathrm{CaCO}_{3}$ or with the $\mathrm{Ca}^{2+}$ ions ${ }^{16}$. If this level is high in the sand, there will be competition in the reaction and the $\mathrm{MgO}$ may not respond satisfactorily.

The sand used in the production of mortars has a $\mathrm{CaO}$ content of only $0.20 \%$ (Table 1 ), which is considered low, and therefore will not influence the formation reactions of these composite materials.

The automotive industry generates large and variable quantities of wastes. These include grinding dust, a hazardous waste (class I) generated in the clutch disc finishing process by grinding and polishing.

Table 1. Chemical compositions of magnesium oxide (MgO), ammonium dihydrogen monophosphate $\left(\mathrm{NH}_{4} \mathrm{H}_{2} \mathrm{PO}_{4}, \mathrm{ADP}\right)$, sodium tripolyphosphate $\left(\mathrm{Na}_{5} \mathrm{P}_{3} \mathrm{O}_{10}, \mathrm{STPP}\right)$ and sand, estimated by XRF (oxides).

\begin{tabular}{lcccc}
\hline Component & MgO & ADP & STPP & Sand \\
\hline $\mathrm{MgO}(\%)$ & 90.48 & 2.31 & 0.13 & --- \\
$\mathrm{SiO}_{2}(\%)$ & 3.76 & 0.41 & 0.33 & 95.33 \\
$\mathrm{Fe}_{2} \mathrm{O}_{3}(\%)$ & 2.78 & 2.58 & $<0.01$ & 0.64 \\
$\mathrm{CaO}(\%)$ & 2.49 & 1.66 & 0.07 & 0.20 \\
$\mathrm{Al}_{2} \mathrm{O}_{3}(\%)$ & 0.35 & 0.90 & 0.34 & 1.91 \\
$\mathrm{MnO}(\%)$ & 0.14 & --- & $<0.01$ & --- \\
$\mathrm{P}_{2} \mathrm{O}_{5}(\%)$ & --- & 91.38 & 59.52 & --- \\
$\mathrm{Na}_{2} \mathrm{O}(\%)$ & --- & 0.17 & 39.56 & 0.15 \\
$\mathrm{~K}_{2} \mathrm{O}(\%)$ & --- & 0.10 & --- & 0.91 \\
$\mathrm{TiO}_{2}(\%)$ & --- & 0.42 & 0.06 & 0.32 \\
$\mathrm{LOI}^{\mathrm{a}}(\%)$ & 0.35 & --- & --- & 0.47 \\
\hline
\end{tabular}


Table 2 presents the results of leaching and solubilization tests that classify the grinding dust as "hazardous" (class I). The main problem of this waste is its lead content, which is about eight times higher than the maximum allowed in the leaching test according to the Brazilian NBR 10004 standard ${ }^{17}$. Sodium, cyanides, phenols, sulfates and surfactants also show levels exceeding the maximum allowed in the solubilization test.

The material is particulate and quite complex due to its diverse constituents (metallic and polymeric fibers as well as fiberglass). This type of waste was used here. The scanning electron microphotographs exhibiting the morphology of grinding dust are shown in Figure 2.

As can be seen in Figure 2, the shape of the particles is quite different. Therefore, the organic fraction was separated from the inorganic fraction by sedimentation and they were observed separately. The organic fraction has various forms ranging approximately cubic, largely undefined (Figure 2a) or even in the form of flat plate (Figure 2b). The inorganic part is in the form of rods (Figures 2c, d), which are glass fibers (characterized by EDS), the diameter of about $10 \mathrm{~mm}$ and length vary, with values higher than 900 micrometers. It can be also observed that these bats are solid, according to micrograph $2 \mathrm{~d}$, which is of fundamental importance
Table 2. Result of the leaching and solubilization test, according to the NBR $10004 / 2004$ standard $^{17}$, which classifies the grinding dust as a hazardous waste (class I).

\begin{tabular}{lcccc}
\hline \multirow{2}{*}{ Parameters } & \multicolumn{2}{c}{ Solubilization } & \multicolumn{2}{c}{ Leaching } \\
\cline { 2 - 5 } & $\begin{array}{c}\text { Result } \\
(\mathbf{m g} / \mathbf{L})\end{array}$ & $\begin{array}{c}\mathbf{M V A}^{\mathbf{b}} \\
(\mathbf{m g} / \mathbf{L})\end{array}$ & $\begin{array}{c}\text { Result } \\
(\mathbf{m g} / \mathbf{L})\end{array}$ & $\begin{array}{c}\mathbf{M V A}^{\mathrm{b}} \\
(\mathbf{m g} / \mathbf{L})\end{array}$ \\
\hline Barium & 0.300 & 0.700 & 0.100 & 70.000 \\
Cadmium & $<0.002$ & 0.005 & $<0.002$ & 0.500 \\
Lead & $<0.010$ & 0.010 & $\mathbf{7 . 8 0 0}$ & $\mathbf{1 . 0 0 0}$ \\
Cooper & 0.090 & 2.000 & $\mathrm{x}$ & $\#$ \\
Selenium & $<0.010$ & 0.010 & $<0.010$ & 1.000 \\
Sodium & $\mathbf{3 4 0 . 0 0}$ & $\mathbf{2 0 0 . 0 0 0}$ & $\mathrm{x}$ & $\#$ \\
Zinc & 0.100 & 5.000 & $\mathrm{x}$ & $\#$ \\
Cyanide & $\mathbf{0 . 4 0 0}$ & $\mathbf{0 . 0 7 0}$ & $\mathrm{x}$ & $\#$ \\
Chlorides & 24.900 & 250.000 & $\mathrm{x}$ & $\#$ \\
Phenols & $\mathbf{1 . 6 0 0}$ & $\mathbf{0 . 0 1 0}$ & $\mathrm{x}$ & $\#$ \\
Fluorids & $<0.010$ & 1.500 & $<0.010$ & 150.000 \\
Nitrates & 0.100 & 10.000 & $\mathrm{x}$ & $\#$ \\
Sulfates & $\mathbf{2 5 0 . 1 0 0}$ & $\mathbf{2 5 0 . 0 0 0}$ & $\mathrm{x}$ & $\#$ \\
Surfactants & $\mathbf{0 . 5 0 0}$ & $\mathbf{0 . 5 0 0}$ & $\mathrm{x}$ & $\#$ \\
\hline
\end{tabular}

${ }^{\mathrm{b}} \mathrm{MVA}=$ Maximum Value Allowed by the NBR 10004/2004 standard ${ }^{17}$ $\mathrm{x}=$ not required by the NBR 10004/2004 standard. \# = absence of a limit established by the NBR 10004/2004 standard $^{17}$.
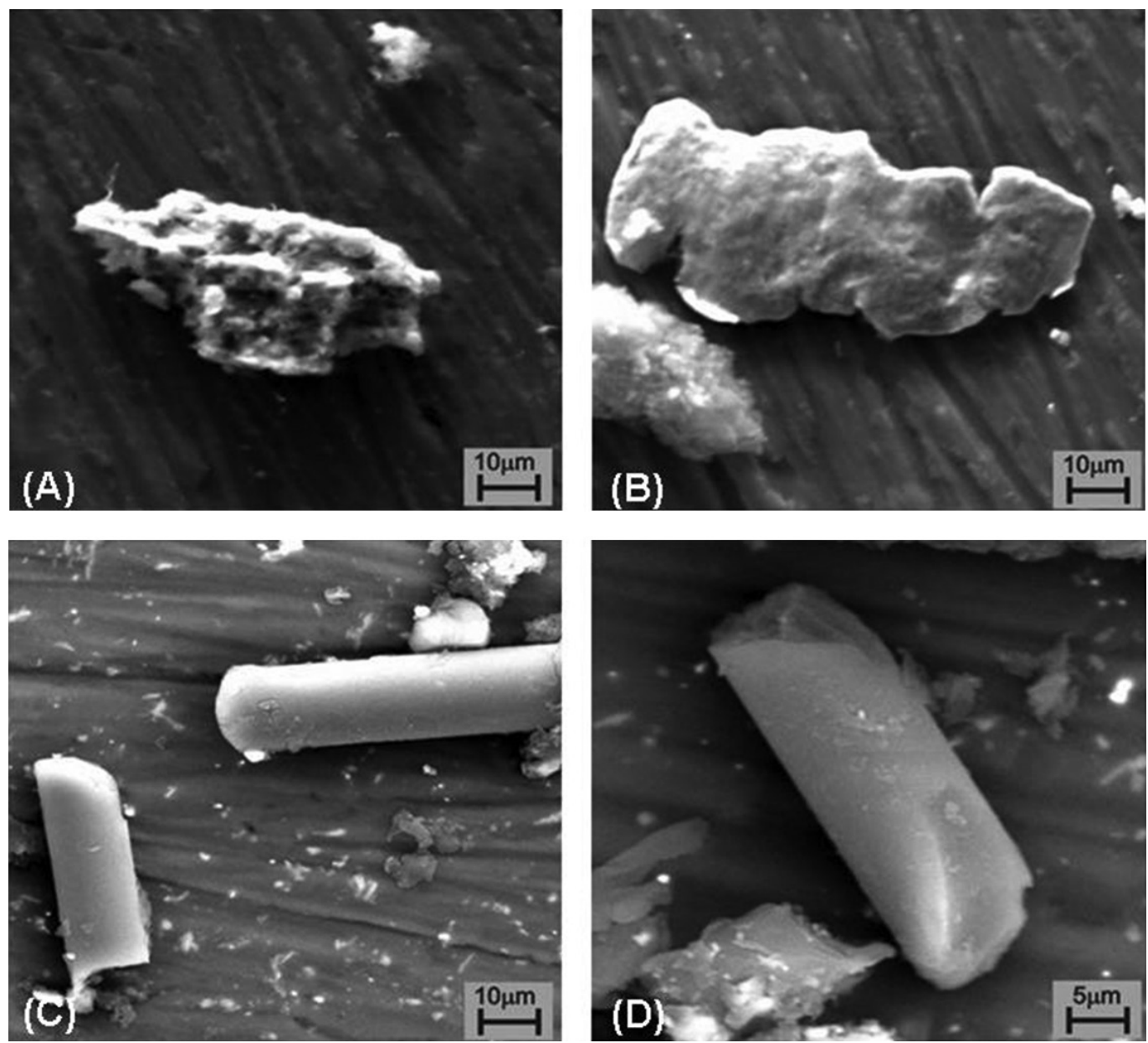

Figure 2. SEM of grinding dust (scattered morphology). 
because, if it were hollow, it would completely alter the amount of water needed for the development of the mix proportions of the compositions.

Grinding dust was supplied from the ZF Sachs of Brazil factory, São Bernardo do Campo, Brazil. It had a surface area of $1.32 \mathrm{~m}^{2} / \mathrm{g}$, specific gravity $2.08 \mathrm{~kg} / \mathrm{dm}^{3}$. Figure 3 shows the obtained diffraction spectrum that allows us to identify the different hydroxides present.

\subsection{Methods}

\subsubsection{Dosage and molding of specimens}

The raw materials were physic-chemically characterized and the ratios among the components were determined, in weight. The "reference proportion" used in the molding of the specimens was 1.0: 0.75: 0.10: 0.30: 0.50 (or 1.0) : 0.5 (MgO: ADP: boric acid: STPP: sand: $\mathrm{H}_{2} \mathrm{O}$ ). Cylindrical specimens (50 $\mathrm{mm}$ in diameter and $100 \mathrm{~mm}$ in length) of magnesium phosphate cement containing different amounts of grinding dust ( $0 \%$ to $40 \%$ in weight) were molded.

\subsubsection{UV-radiation accelerated aging test}

The accelerated aging test was conducted using an Atlas Weather-Ometer piece of equipment, operating with a xenon lamp. The machine has a rotary carousel and automatic controls for temperature and relative humidity inside the aging chamber. This device, which uses a xenon lamp with an emission source of energy is responsible for the accelerated aging of the samples studied and it proved effective in reproducing the conditions of natural aging.

The test correlation estimated is that 1200 hours (50 days) of artificial accelerated exposure amounts to about one year of natural aging. The test conditions are shown in Table 3.

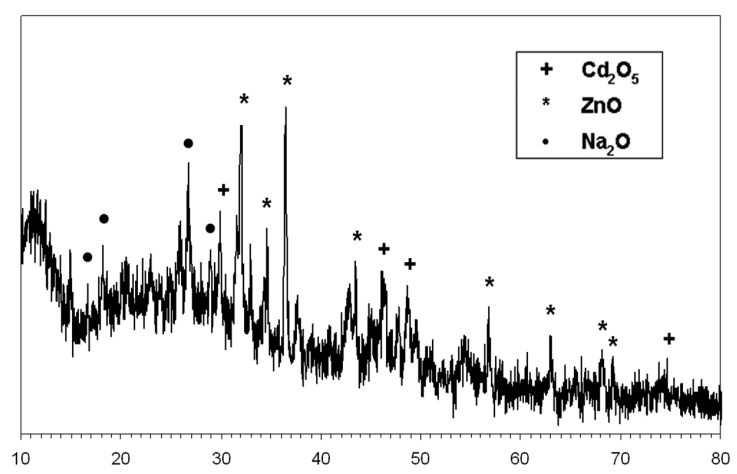

Figure 3. X-ray diffraction analysis of grinding dust showing the identified species present. $X$-axis corresponds to Bragg's angle $2 \varphi$.

\subsubsection{Mechanical strength}

The values of axial compression correspond to the average of 3 values for each magnesium phosphate composition and mortar age (3, 7 and 28 days after molding), and were obtained with an Instron 5500R universal testing machine and a load of $1.5 \mathrm{~mm} / \mathrm{min}$. The specimens that presented an error of more than $5 \%$ were excluded and replaced by others, following the procedure established by the Brazilian NBR 7222 standard (Mortar and concrete - Determination of the tensile strength of cylindrical specimens subjected to diametral compression - Test method) ${ }^{18}$.

\subsubsection{Leaching and solubilization tests}

The Brazilian standard NBR 10004 ("Solid waste - Classification") ${ }^{17}$ classifies solid wastes and their potential risks to the environment and public health so that they can be managed properly and is based on the American Code of Federal Regulation (CFR) - Title 40 - Protection of environmental - Part 260-265 - Harzardous waste management ${ }^{19}$. Therefore, wastes and composites containing them are classified as "hazardous" (class I) or "nonhazardous" (II-A non-inert, and II-B inert).

\section{Results and Discussion}

The mortar specimens with their different contents of waste and sand were subjected to accelerated aging by ultraviolet (UV) radiation, simulating aging for 1 year. The specimens were tested at the natural age of 28 days and after accelerated aging. The choice of testing-ages was purely operational so that the results could be compared. The arrangement of samples in the artificial aging machine can be seen in Figure 4.

After 50 days (1200 hours) undergoing artificial aging, the specimens were removed and mechanical tests (axial compression) to evaluate the durability were carried out. Visually, the color of specimens changed after accelerated aging, i.e. the bodies were whitish, similar to Portland cement artifacts after natural aging. These changes can be seen in Figure 5, where specimens of whitish appearance (in front) were subjected to accelerated aging.

According to the mechanical characterization (before and after accelerated aging), it was observed that there was a reduction of around $17 \%$ in the resistance in mortars with a sand content of 0.5 and around $25 \%$ in mortars with a sand content of 1.0, regardless of residue content, as can be seen in Figure 6.

This behavior has been observed in previous studies, when Seehra et al. ${ }^{20}$ found that durability is very dependent on curing conditions and if the specimens are wet or dry. During two years of research under dry condition, no evidence of a decrease in resistance for a commercial

Table 3. Test conditions of accelerated aging by UV radiation, according to ASTM G-155-00 standard ${ }^{21}$.

\begin{tabular}{|c|c|}
\hline Equipament & Atlas Weather-Ometer modelo 65 XW-WR1. \\
\hline Radiation Source & 6500W Xenon lamp, with internal and external filters of boron. \\
\hline Irradiance & $0,35 \mathrm{~W} / \mathrm{m}^{2}$ and $340 \mathrm{~nm}$ \\
\hline Accelerated aging cycle for each 120 minutes & 102 minutes of sunshine and 18 minutes of sunshine and rainfall simulation. \\
\hline
\end{tabular}



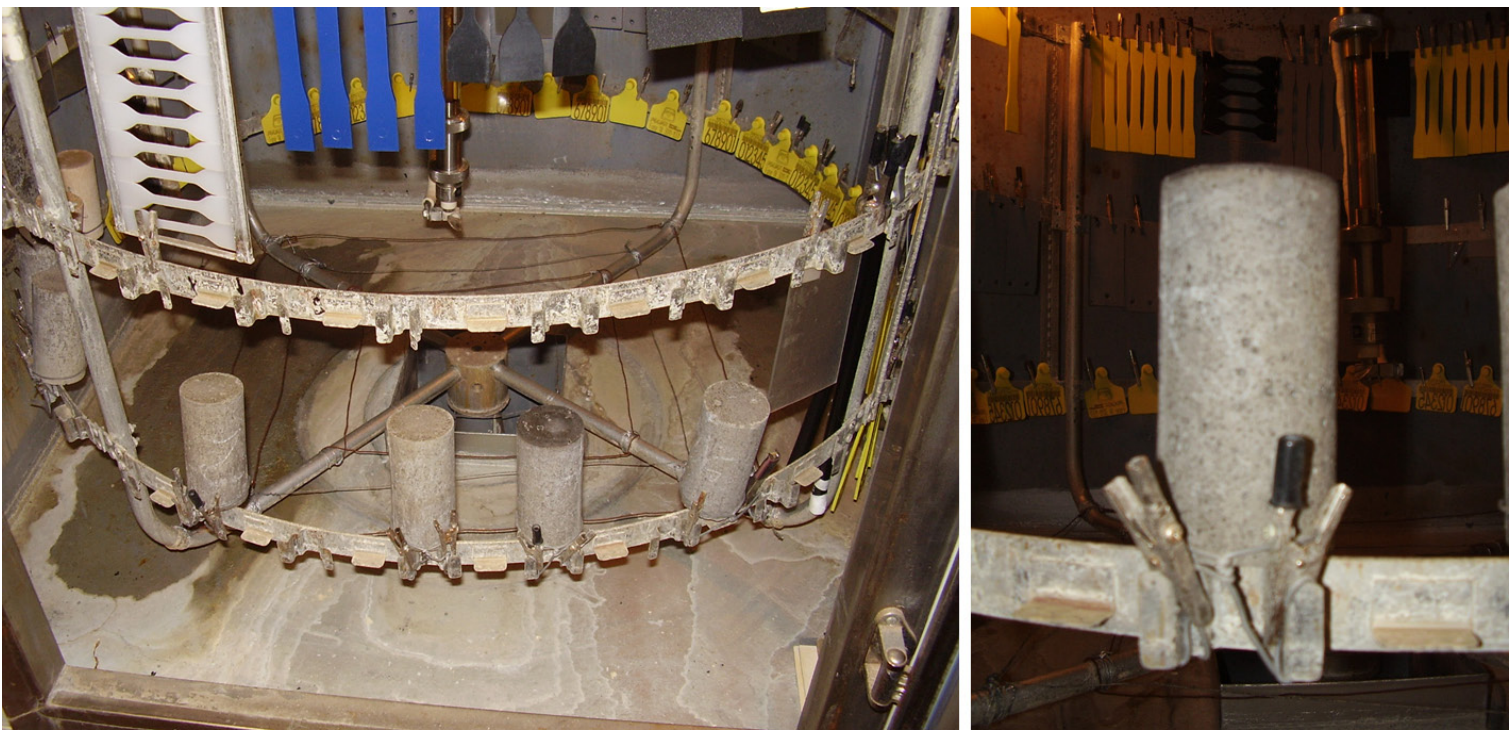

Figure 4. Position of the samples in the accelerated aging machine.

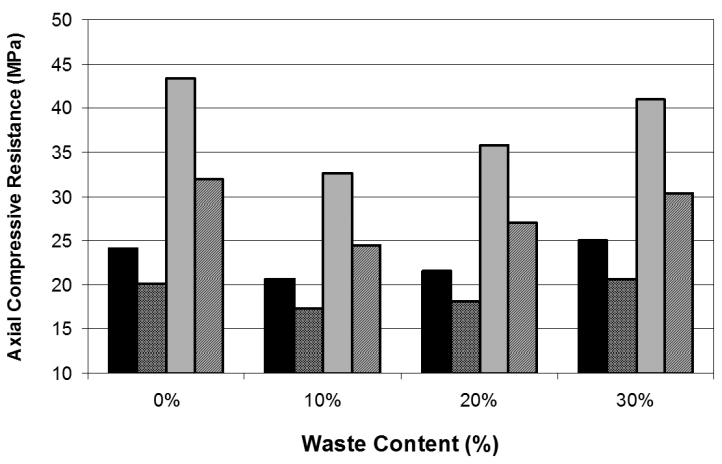

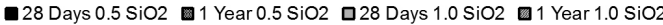

Figure 5. Changes in the appearance of magnesium phosphate cement matrices after being subjected to accelerated aging by ultraviolet (UV) radiation.

product was verified. However, under humid conditions (such as in the present work), there was a decrease in resistance, but the results were still satisfactory in absolute values. This regression can be attributed to the fact that the phosphate hydrates, especially struvite, are highly soluble in water.

This behavior is very interesting because the mortars without grinding dust in their composition also experienced this decrease in resistance $(16.6 \%$ and $24.3 \%)$ in the same magnitude as other mortar compositions containing waste. Thus, this degradation cannot be accredited to the presence of residue, which again shows the effectiveness of encapsulation of this material in the magnesium phosphate cement matrix. This behavior can therefore be associated with excessive loss of water, including the degradation of struvite, and a consequent increase in porosity. Despite this decrease in resistance, this occurred to the same extent in all compositions, as seen in Figure 7.

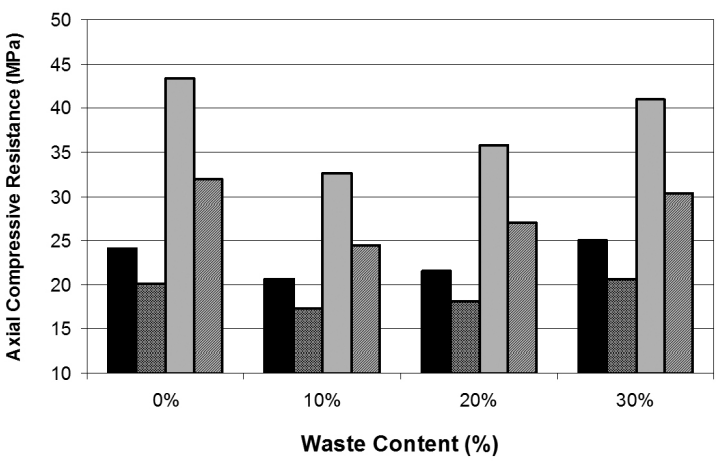

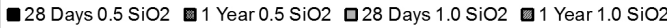

Figure 6. Variation in compressive strength of magnesium phosphate cement mortars containing grinding dust, artificially aged for a period equivalent to one year.

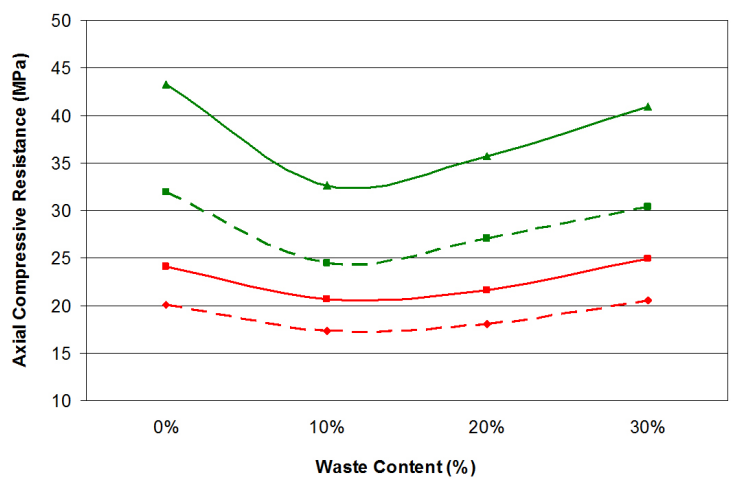

Figure 7. Variation in the compressive strength of magnesium phosphate cement mortar artificially aged for a period equivalent to one year, as a function of waste content added to the samples, compared with specimens with natural age of 28 days. 
The high loss of mass in the mortars (with 0.5 and 1.0 contents of sand) that reached $10 \pm 1 \%$ and $19 \pm$ $1 \%$, respectively is noteworthy. This is associated with an increase in the porosity and a decrease in mechanical strength. The volume reduction of the specimens was negligible, not reaching $1 \%$. The loss of mass and the volume reduction of the specimens after being subjected to artificial aging are shown in Table 4.

Another aspect related to the durability and observed in the samples was the appearance of efflorescence at the surface of specimens that were cured in a high humidity atmosphere $(\mathrm{RH}=70 \pm 5 \%)$. Efflorescence appeared in all specimens and were not related to waste content added, as can be seen in Figure 8a. The efflorescence dust was collected carefully from the body surface so that it could be analyzed (Figure $8 \mathrm{~b}$ ).

The florescence can be divided into two major groups: sub-florescence and efflorescence. The sub-florescence is not visible because the salt deposits are formed below the surface of the piece, whereas in the efflorescence the salt deposits form on the surface of the ceramic products resulting from the migration and evaporation of aqueous saline solutions ${ }^{22}$. The florescence can be present as powdery deposits or deposits with color changes on the surface of coatings, in whitish, grayish, greenish, yellowish or black ${ }^{23}$ tones and it is not usually a structural problem, but an esthetic problem. However, because it is a complex phenomenon, with economic consequences, it worries manufacturers and builders. Efflorescences are usually a white powder and may be present on the mortars as a veil (as seen in Figure 8a).
Soluble salts that give rise to efflorescences come from the raw materials, the water or the environment ${ }^{22}$. Among these soluble salts are those especially formed with alkali and alkaline earth metals, such as sulfates and carbonates of sodium and potassium, $\mathrm{MgO}, \mathrm{MgCO}_{3}, \mathrm{MgF}_{2}, \mathrm{CaO}, \mathrm{CaCO}_{3}$ and $\mathrm{CaF}_{2}$. The alkaline earth metals, after reacting with water release $\mathrm{H}_{2}$ and form hydroxides of metal. Moreover, it is worth remembering that the silicates are insoluble, so this type of element is not a causative agent of efflorescence ${ }^{23}$.

The aqueous solution is formed inside the specimen by contact between the water and soluble salts present in the material, or is derived from external sources and moves from one part of the structure to another through the capillary network of the material. Thus, the conditions required for the formation of these deposits in concrete and masonry are the coexistence of water, water-soluble salts, and environmental structural conditions which enable the percolation and the evaporation of water (hydrostatic pressure) $)^{24-26}$. Evaporation of the salt aqueous solution may occur on the surface or in regions near this, only when a moisture gradient between the ambient atmosphere and the material which promotes this phenomenon is present ${ }^{22}$.

The phases present on efflorescence powder were verified by X-ray diffraction (XRD). As can be seen in Figure 9. The main compounds found at the surface of specimens are formed by alkali and alkaline earth metals, as was expected. The compounds were: sodium phosphate $\left[\mathrm{Na}_{3} \mathrm{PO}_{4}\right]$, sodium hydrogen phosphite hydrate $\left[\mathrm{Na}_{3} \mathrm{HP}_{2} \mathrm{O}_{5} .12 \mathrm{H}_{2} \mathrm{O}\right]$, the unreacted magnesium oxide $[\mathrm{MgO}]$, sodium hydrogen carbonate $\left[\mathrm{Na}_{3} \mathrm{H}\left(\mathrm{CO}_{3}\right)_{2}\left(\mathrm{H}_{2} \mathrm{O}\right)_{2}\right]$, magnesium phosphate $\left[\mathrm{Mg}_{3}\left(\mathrm{PO}_{4}\right)_{2}\right]$ and the sodium-calcium carbonate [Natrofairchildite, $\mathrm{Na}_{2} \mathrm{Ca}\left(\mathrm{CO}_{3}\right)_{2}$ ]. The formation

Table 4. Mass loss $(\Delta \mathrm{M})$ and volume reduction $(\Delta \mathrm{V})$ of the magnesium phosphate cement mortars containing grinding dust, subjected to accelerated aging for a period equivalent to one year.

\begin{tabular}{cccccccccccc}
\hline \multirow{2}{*}{$\begin{array}{c}\text { Waste Content } \\
\text { Composition }\end{array}$} & \multicolumn{2}{c}{$\mathbf{0 \%}$} & \multicolumn{2}{c}{$\mathbf{1 0 \%}$} & \multicolumn{2}{c}{$\mathbf{2 0 \%}$} & \multicolumn{3}{c}{$\mathbf{3 0 \%}$} & \multicolumn{2}{c}{$\mathbf{4 0 \%}$} \\
\cline { 2 - 13 } & $\Delta \mathbf{M}$ & $\Delta \mathbf{V}$ & $\Delta \mathbf{M}$ & $\Delta \mathbf{V}$ & $\Delta \mathbf{M}$ & $\Delta \mathbf{V}$ & $\Delta \mathbf{M}$ & $\Delta \mathbf{V}$ & $\Delta \mathbf{M}$ & $\Delta \mathbf{V}$ \\
\hline Mortars - $0.5 \mathrm{SiO}_{2}$ & $9.51 \%$ & $0.88 \%$ & $10.32 \%$ & $0.65 \%$ & $11.10 \%$ & $0.70 \%$ & $9.45 \%$ & $0.84 \%$ & $9,81 \%$ & $0.74 \%$ \\
Mortars - $1.0 \mathrm{SiO}_{2}$ & $9.50 \%$ & $0.52 \%$ & $11.30 \%$ & $0.66 \%$ & $10.04 \%$ & $0.60 \%$ & $10.11 \%$ & $0.54 \%$ & $10,34 \%$ & $0.62 \%$ \\
\hline
\end{tabular}
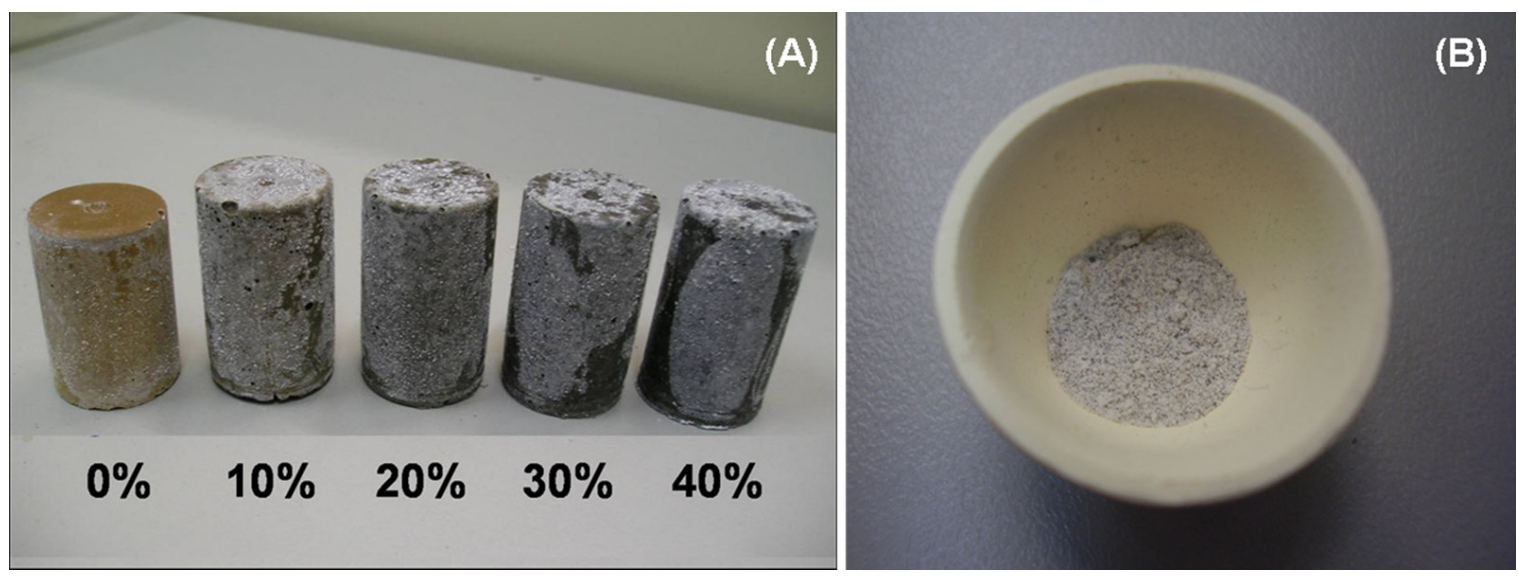

Figure 8. Pictures of samples at 28 days of age that presented efflorescence on their surfaces (A) and efflorescence powder scrapings from the surface of the specimens (B). 
of these compounds can be avoided by a rigorous control of humidity during the cure process (low humidity) and higher material densification, so that there is lower porosity in order to avoid the soluble salts from leaching.

To supplement the durability analysis of the magnesium phosphate cement containing grinding dust, the mortar samples with $20 \%$ and $30 \%$ waste addition subjected to artificial aging were environmentally analyzed to verify the influence of aging in the encapsulation of hazardous elements. The comparative results are shown in Table 5. Only the results of solubilized extracts are presented because the leaching results were well below the maximum allowed by the Brazilian standard NBR $10004^{17}$.

Comparing the results obtained for the samples after natural aging (28 days) and with those obtained in the samples artificially aged for a period equivalent to one year, it is observed that most of the hazardous elements

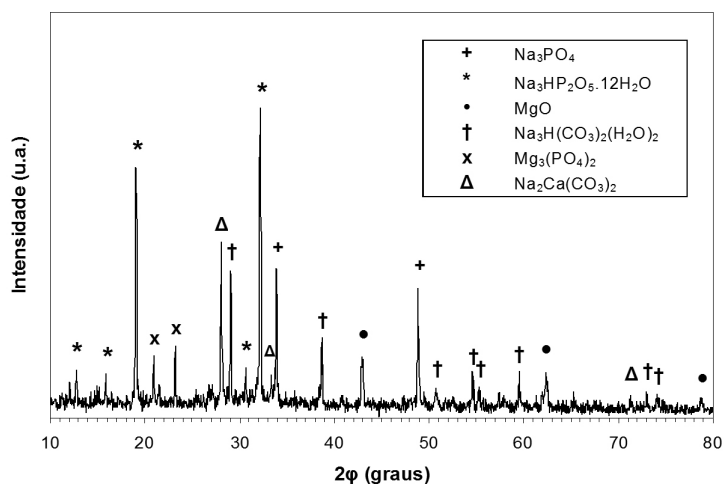

Figure 9. XRD pattern of efflorescence powder, obtained from the surface of magnesium phosphate cement mortars containing powder grinding. present remain in very similar concentrations and the values of some elements (copper, chromium, sodium, zinc and iron) deceased. This decrease was significant for copper, which was removed from the group of elements with concentrations above that the maximum value allowed. Only the cyanide concentration in the solubilized extract increased after artificial aging, remaining above the tolerable concentration. As there was no evidence at concentrations above the maximum value allowed (MVA) in leached extracts, magnesium phosphate cement mortars can be classified as a Class II-A material (non-hazardous non-inert), according to Brazilian standard NBR $10004^{17}$. These results show the effectiveness of grinding dust encapsulation in the magnesium phosphate cement matrix.

\section{Conclusions}

The analyses of the results of mechanical resistance, loss of weight and volume, the presence of efflorescence, and especially from the environmental analysis (leaching and solubilization) led to the following conclusions:

- There is a decrease in the compressive strength of the mortar between 28 days and 1 year of age, which was around $17 \%$ for mortars with sand content of 0.5 and $25 \%$ for mortars with sand content 1.0 , regardless of the amount of waste incorporated. Thus, it can be concluded that a loss in performance is not associated with the presence of this waste;

- The main compounds observed in the efflorescence found on the surface of the specimens are formed by alkali metals and alkaline earth metals. The formation of these compounds can be avoided by a rigorous control of humidity during the cure process (low humidity) and higher material densification, so that there is lower porosity in order to avoid the leaching of soluble salts;

Table 5. Comparison of the solubilization tests of magnesium phosphate cement mortars, as a function of grinding dust contents after 28 days and 1 year of age.

\begin{tabular}{|c|c|c|c|c|c|}
\hline \multirow[t]{2}{*}{ Parameters } & $20 \%-28$ days & $20 \%-1$ year & $30 \%-28$ days & $30 \%-1$ year & $\mathbf{M V A}^{\mathbf{c}}$ \\
\hline & $\mathrm{mg} / \mathrm{L}$ & $\mathrm{mg} / \mathrm{L}$ & $\mathrm{mg} / \mathrm{L}$ & $\mathrm{mg} / \mathrm{L}$ & $\mathrm{mg} / \mathrm{L}$ \\
\hline Barium & 0.005 & 0.005 & 0.006 & 0.010 & 0.700 \\
\hline Cadmium & $<0.002$ & $<0.002$ & $<0.002$ & $<0.002$ & 0.005 \\
\hline Lead & $<0.010$ & $<0.010$ & $<0.010$ & $<0.010$ & 0.010 \\
\hline Cooper & 4.500 & $<0.003$ & 4.800 & 0.040 & 2.000 \\
\hline Total Chromium & 0.040 & $<0.006$ & 0.040 & $<0.006$ & 0.050 \\
\hline Manganese & 0.010 & 0.010 & 0.060 & 0.020 & 0.100 \\
\hline Silver & $<0.004$ & $<0.004$ & $<0.004$ & $<0.004$ & 0.050 \\
\hline Sodium & 156.200 & 113.000 & 162.700 & 147.700 & 200.000 \\
\hline Zinc & 0.800 & 0.005 & 0.700 & 0.600 & 5.000 \\
\hline Iron & 0.200 & 0.010 & 0.200 & $<0.002$ & 0.300 \\
\hline Cyanides & 0.300 & 0.800 & 0.500 & 1.100 & 0.070 \\
\hline Chlorides & 1.900 & 2.400 & 4.300 & 3.800 & 250.000 \\
\hline Phenols & $<0,010$ & $<0.010$ & $<0.010$ & $<0.010$ & 0.010 \\
\hline Nitrates & 1.000 & 2.00 & 2.200 & 1.700 & 10.000 \\
\hline Sulfates & 270.100 & 269.400 & 256.100 & 302.700 & 250.000 \\
\hline Surfactants & 0.200 & 0.300 & 0.200 & 0.300 & 0.500 \\
\hline
\end{tabular}

${ }^{c} \mathrm{MVA}=$ Maximum Value Allowed by the NBR 10004/2004 standard ${ }^{17}$ 
- After artificially aging, most of the hazardous elements present remain in very similar concentrations and these rates decreased in some cases (copper, chromium, sodium, zinc and iron). Only the cyanide concentration in the solubilized extract increased over time, remainingabove the tolerable concentration;

- Magnesium phosphate cement mortar is a reliable material for the encapsulation of hazardous elements and lasts for reasonable periods of time.

\section{References}

1. Sarkar AK. Phosphate cement-based fast-setting binders. Ceramic Bulletin. 1990; 69(2):234-237.

2. Ribeiro DV and Morelli MR. Influence of the addition of grinding dust to a magnesium phosphate cement matrix. Construction and Building Materials. 2009; 23(9):3094-3102. http://dx.doi.org/10.1016/j.conbuildmat.2009.03.013

3. Roy D. New strong cement materials: Chemically bonded ceramics. Science. 1987; 235:651-658. PMid:17833626. http:// dx.doi.org/10.1126/science.235.4789.651

4. Soudée E and Péra J. Mechanism of setting reaction in magnesia - phosphate cements. Cement and Concrete Research. 2000; 30(2):315-321. http://dx.doi.org/10.1016/ S0008-8846(99)00254-9

5. Sarkar AK. Hydration/dehydration characteristics of struvite and dittmarite pertaining of magnesium ammonium phosphate cement systems. Journal of Materials Science. 1991; 26(12):2514-2518. http://dx.doi.org/10.1007/ BF01130204

6. Wagh AS, Singh D and Jeong SY. Chemically bonded phosphate ceramics: I, A dissolution model of formation. Journal of the American Ceramic Society. 2003; 86(11):18381844. http://dx.doi.org/10.1111/j.1151-2916.2003.tb03569.x

7. Torras J, Buj I, Rovira M and Pablo J. Semi-dynamic leaching tests of nickel containing wastes stabilized/ solidified. Journal of Hazardous Materials. 2011; 186(23):1954-1960. PMid:21247689. http://dx.doi.org/10.1016/j. jhazmat.2010.12.093

8. Singh D, Mandalika VR, Parulekar SJ and Wagh AS. Magnesium potassium phosphate ceramic for 99Tc immobilization. Journal of Nuclear Materials. 2006; 348: 272-282. http://dx.doi. org/10.1016/j.jnucmat.2005.09.026

9. Buj I, Torras J, Casellas D, Rovira M and Pablo J. Effect of heavy metals and water content on the strength of magnesium phosphate cements. Journal of Hazardous Materials. 2009; 170(1):345-350. PMid:19473758. http:// dx.doi.org/10.1016/j.jhazmat.2009.04.091

10. Buj I, Torras J, Casellas D, Rovira M and Pablo J. Leaching behaviour of magnesium phosphate cements containing high quantities of heavy metals. Journal of Hazardous Materials. 2010; 175(2):789-794. PMid:19932557. http:// dx.doi.org/10.1016/j.jhazmat.2009.10.077

11. Vinokurov SE, Kulyako YM, Slyuntchev OM, Rovny SI and Myasoedov BF. Low-temperature immobilization of actinides and other components of high-level waste in magnesium potassium phosphate matrices. Journal of Nuclear Materials. 2009; 385(4):189-192. http://dx.doi.org/10.1016/j. jnucmat.2008.09.053

12. Yang $\mathrm{Q}$ and $\mathrm{Wu} X$. Factors influencing properties of phosphate cement - based binder for rapid repair of concrete. Cement and Concrete Research. 1999; 29(3):389-396. http://dx.doi. org/10.1016/S0008-8846(98)00230-0

\section{Acknowledgements}

The authors wish to thank CNPq - National Council for Scientific and Technological Development (Brazil), State of São Paulo Research Foundation (FAPESP), PPGCEM/UFSCar - Postgraduate Program in Materials Science and Engineering at the Federal University of São Carlos (Brazil), and ZF SACHS of Brazil Ltda.

13. Hall DA, El-Jazairi B and Stevens R. The effect of retarders on the microstructure and mechanical properties of magnesia - phosphate cement mortar. Cement and Concrete Research. 2001; 31(3):455-465. http://dx.doi.org/10.1016/ S0008-8846(00)00501-9

14. Abdelrazig BEI, Sharp JH and El-Jazairi B. The Chemical composition of mortars made from magnesia - phosphate cement. Cement and Concrete Research. 1998; 18(3):415-425. http://dx.doi.org/10.1016/0008-8846(88)90075-0

15. Argonne National Laboratory. Chemically Bonded Phosphate Ceramics: Cementing de Gap between ceramics, cements and polymers. Available from: <http://www.techtranfer.anl. gov/ techtour/ceramicrete-pubs.html>. Access in: 22/10/2011.

16. Yang Q, Zhu B, Zhang S and Wu X. Properties and applications of magnesia-phosphate cement mortar for rapid repair of concrete. Cement \& Concrete Composites Journal. 2000; 30(11):1807-1813. http://dx.doi.org/10.1016/ S0008-8846(00)00419-1

17. Associação Brasileira de Normas Técnicas - ABNT. NBR 10004: Resíduos Sólidos - Classificação. Rio de Janeiro: ABNT; 2004. 71 p.

18. Associação Brasileira de Normas Técnicas-ABNT. NBR 7222: Mortar and concrete - Determination of the tensile strength of cylindrical specimens subjected to diametral compression Test method. Rio de Janeiro: ABNT; 2011. 5 p.

19. American Code of Federal Regulation - CFR. Title 40 Protection of environmental - Part 260-265 - Harzardous waste management. CFR; 2010. p. 260-265.

20. Seehra SS, Gupta S and Kumar S. Rapid setting magnesium phosphate for quick repair of concrete pavements - Characterisation and durability aspects. Cement and Concrete Research. 1993; 23(2):254-266. http://dx.doi. org/10.1016/0008-8846(93)90090-V

21. American Society for Testing and Materials -ASTM. G155-00: Standard Practice for Operating Xenon Arc Light Apparatus for Exposure of Non-Metallic Materials. ASTM; 2000. 7 p.

22. Menezes RR, Ferreira HS, Neves GA and Ferreira HC. Soluble salts and efflorescence of ceramic bricks and other building materials - review. Cerâmica. 2006; 52(321):37-49. http:// dx.doi.org/10.1590/S0366-69132006000100006

23. Souza GF. Efflorescence in coating mortars. In: Proceendings of Second Brazilian Symposium of Mortar Technology; 2007; Salvador. Salvador; 2007, p. 344-356.

24. Bauer LAF. Construction Materials 1. 5th ed. Rio de Janeiro: LTC; 1994. 435 p.

25. Uemoto KL. Pathology: Damage caused by efflorescence. In: Buildings Technology. São Paulo: PINI; 1988. p. 561-564.

26. Neves C. Influence of soluble chlorides and sulfates in mortar properties. In: Proceedings of Second Brazilian Symposium of Mortar Technology; 2007; Salvador. Salvador; 2007. p. 208-215. 